\title{
Pequenas resistências: contação de histórias, performance e protagonismo infantil na escola
}

Small resistances: storytelling, performance
and children's protagonism in school

Luciana Hartmann ${ }^{1}$

Sonaly Torres Silva ${ }^{2}$ 


\section{Resumo}

Este artigo analisa performances de contação de histórias realizadas em coautoria com estudantes do Ensino Fundamental de escolas públicas de Minas Gerais e do DF, que adotam como eixo transversal a questão da diversidade cultural na escola. Pautadas metodologicamente pela pedagogia das artes cênicas e pelos estudos da performance, são desenvolvidas experiências de partilha e produção de histórias com as crianças, nas quais o protagonismo infantil é enfatizado. Nos diferentes processos analisados, verificamos que a partilha de histórias engendra pequenas resistências no contexto escolar, contribuindo para que as crianças sejam aceitas e respeitadas em suas singularidades.

Palavras-chave: Contação de histórias; diversidade cultural; performance; escola; protagonismo infantil

\section{Abstract}

This article analyzes storytelling performances carried out in co-authorship with young students from public schools from Minas Gerais and DF, adopting as transverse axis the issue of cultural diversity in the school. Guided methodologically by theatre pedagogy and performance studies, experiences in which children's protagonism is emphasized, sharing and producing stories with them. In the different analyzed processes, we verified that the sharing of stories produces small resistances in the school context, contributing to accepted and respected children in their singularities.

Keywords: Storytelling; cultural diversity; performance; school; children

E-ISSN: 2358.6958

1 Professora Doutora Associada na Universidade de Brasília (UnB). Antropóloga e contadora de histórias. Bolsista de Produtividade em Pesquisa do CNPq - nível 2. luhartm71@gmail.com

2 Pesquisadora e contadora de histórias. Doutoranda no Programa de Pós-Graduação Interdisciplinar em Performances Culturais da Universidade Federal de Goiás (UFG).sonalytsg@gmail.com 
A prática da contação de histórias é bastante comum em escolas brasileiras, sobretudo na Educação Infantil e nos anos iniciais do Ensino Fundamental. O rico repertório da literatura infantil, brasileira ou estrangeira, é frequentemente acionado por professoras e professores, proporcionando momentos de aprendizado por meio do encantamento, da fantasia, da ficção. Percebemos, no entanto, que a voz que conta a história, prioritariamente, é a do adulto. Nossa abordagem vem sendo, já há alguns anos, abrir a roda para que as vozes dos pequenos e pequenas também tenham vez. Atualmente, é por meio do projeto "Crianças protagonistas: artes cênicas e diversidade cultural na escola"3, realizado em escolas públicas de Minas Gerais, de Goiás e do Distrito Federal, que contamos e, sobretudo, escutamos as histórias de crianças. Neste artigo traremos especificamente algumas experiências desenvolvidas em MG e no DF.

Nossas pesquisas são fortemente inspiradas pelo trabalho de Gilka Girardello, contadora de histórias, professora da UFSC, que pesquisa, há mais de 30 anos, narrativas contadas por crianças. Gilka é uma precursora, no Brasil, desta escuta sensível da palavra dos pequenos. Sua obra nos auxilia a navegar pelo mar de histórias infantis, com especial atenção para a diversidade cultural que delas emerge e para o sentido de partilha que elas proporcionam:

\begin{abstract}
Na educação, a partilha de histórias contadas pelas crianças tem um papel muito importante em contextos de diversidade sociocultural. O incentivo a que as crianças narrem contos e casos de suas culturas de origem, fazendo ouvir seus diferentes sotaques e formas de narrar, enriquece o mar dos fios de histórias que banha o grupo, e o senso de comunidade narrativa que toda sala de aula deveria abrigar. E mais potentes serão essas partilhas quanto mais presente estiver a dimensão de autoria das crianças narradoras. (Girardello, 2015, p. 17)
\end{abstract}

Valorizando a escola como espaço privilegiado para a troca de histórias e para a escuta das crianças, temos nos servido de uma combinação de abordagens metodológicas oriundas da antropologia, do teatro e dos estudos da performance.

Partindo de "etnografias propositivas"4 - nas quais o processo de observação é acrescido de propostas de atividades lúdicas com as crianças, como jogos teatrais, canções, brincadeiras tradicionais - histórias vão sendo lembradas, criadas, contadas, performatizadas. O entendimento da performance como possibilidade de ação, crítica e transformação, presente na vida cotidiana, nos conduz às pedagogias performativas, que permitem, segundo a educadora Elise Pineau, a "emergência de uma nova poética dos estudos educacionais" (Pineau, 2010, p. 91). A integração de diferentes elementos, técnicas e experiências nas práticas de contar histórias nos aproxima, ainda, da noção de "pesquisa performativa", ou seja, pesquisa guiada-pela-prática, que é intrinsecamente empírica e prevê que tanto seus processos quanto seus produtos sejam realizados como performances (Haseman, 2015).

\footnotetext{
${ }^{3}$ A pesquisa conta, atualmente, com o apoio do Edital Demanda Espontânea 03/2016, da Fundação de Amparo à Pesquisa do DF (FAPDF) e com a participação de estudantes de graduação, mestrado e doutorado em Artes Cênicas (PPGCEN/UNB) e em Performances Culturais (PPGIPC/UFG).

${ }^{4}$ Este conceito vem sendo desenvolvido a partir da pesquisa de Pós-Doutorado realizada com crianças imigrantes entre 2014-2015, em escolas públicas francesas, com apoio da Coordenação de Aperfeiçoamento de Pessoal de Nível Superior - Brasil (CAPES) - Código de Financiamento 001.
} 
No nosso caso, a pesquisa realizada por meio de performances narrativas produz novas poéticas quando, por exemplo, fazemos a brincadeira do limão - um pequeno ritual através do qual encerramos os encontros com as crianças. Nela, um limão que passa de mão em mão, pelos participantes da roda (crianças e adultos), enquanto se canta uma canção:

\author{
O limão entrou na roda \\ Ele passa de mão em mão \\ Ele vai ele vem \\ Ele ainda não chegou \\ E no meio do caminho \\ A pessoa pegou!
}

Quem ficar com o limão, quando a canção terminar, contará uma história. Uma das histórias que ouvimos durante a pesquisa, por exemplo, foi uma versão para a lenda africana xhosa "O menino grávido". Na história original, um menino desobedece a orientação do sábio da aldeia e come algumas raízes mágicas, que serviriam para engravidar sua mãe. O menino então fica grávido. Na versão narrada em sala de aula, durante a brincadeira do limão, nosso pequeno autor contou que havia um casal que queria ter uma filha, porém a criança nasceu com um pênis, e "fazia xixi em pé". O casal tentou novamente e nasceu um filho diferente, com vagina no lugar do pênis, que "fazia xixi sentado", mas continuava sendo um menino. Tentaram de novo, e dessa vez a criança tinha um bumbum no lugar do pênis. Tentaram mais uma vez e nasceu uma criança com as pernas no lugar dos braços e a cabeça no lugar do bumbum...

A descrição desse episódio permite compreender, como propõe Icle e Bonatto, que a performance "significa, a um só tempo, a ritualização de comportamentos e a possibilidade inventiva de romper com essas repetições." (Icle; Bonatto, 2017, p. 11) Foi justamente a ritualização proposta pela brincadeira do Limão, que possibilitou a transformação da história e a criação de corpos alternativos para o "menino grávido". Essa história foi narrada no âmbito do Ateliê do Brincar, uma das ações de nossa pesquisa que será detalhado abaixo. Nela se podem perceber vários aspectos que serão aprofundados ao longo do artigo, como o protagonismo infantil, a emergência de temas que permitem o debate sobre a diversidade cultural (no caso, a diversidade de gênero) e a presença de pedagogias performativas.

No livro "Criança em Cena", Tiago Cruvinel propõe: "Sejamos observadores atentos ao universo da criança para aprendermos, cada vez mais, sobre a nossa arte." (Cruvinel, 2015, p. 153). Nossa proposta é avançar ainda mais, não apenas observando o universo da criança, mas ampliando os nossos espaços e tempos e tempos de interação, para que ela possa se manifestar, performaticamente, na escola e fora dela.

Um dos objetivos de nossas pesquisas tem sido compreender se e/ou como as performances narrativas das crianças podem suscitar a emergência de resistências diante das diferentes formas de manifestação do poder. Inspiradas em Foucault (1986) entendemos que o poder não é algo transcendente ou uma substância que se possa possuir ou delegar, não é algo imanente, mas se manifesta como prática, exercício. A resistência, por sua vez, é inerente ao poder: onde há exercício de poder 
há resistência. Ressaltamos que nas elaborações do autor, resistência não significa unicamente não ceder diante do poder, mas encontrar saídas alternativas, inovar, inventar, transformar.

Apresentaremos aqui alguns relatos de experiência de partilha de histórias com as crianças, no intuito de observar como as performances de contação de histórias podem suscitar o debate sobre a diversidade cultural no contexto escolar. A problemática que impulsiona essa reflexão é: experiências de performances de contação de histórias em ambientes escolares podem contribuir para emergência de resistências, suscitando o protagonismo das crianças?

\section{Os contextos da pesquisa}

O projeto "Crianças Protagonistas: artes cênicas e diversidade cultural na escola" teve início em 2016, dando continuidade a pesquisas que já viemos realizando com a escuta de crianças do DF, do Uruguai e da França (Hartmann, 2016; 2017; 2018). Nesta fase, o projeto contou com quatro estudantes do Curso de Artes Cênicas da Universidade de Brasília, bolsistas de Iniciação Científica (um bolsista de Ações Afirmativas), e uma bolsista de Apoio Técnico, Licenciada em Artes Cênicas ${ }^{5}$. Inicialmente o grupo dedicou-se à leitura e análise de bibliografia das áreas da Pedagogia das Artes Cênicas e dos Estudos da Infância, que abordassem questões relacionadas à diversidade cultural tanto do ponto de vista teórico quanto metodológico. As leituras foram objeto de debate em reuniões quinzenais do grupo. Os pesquisadores também realizaram fichamentos das leituras, que foram compartilhadas com toda a equipe, compondo um acervo de fichamentos.

Em um segundo momento, estava prevista a realização de práticas artístico- pedagógicas a com alunos do Ensino Fundamental de Escolas Públicas do Distrito Federal. Antes dos membros da equipe irem para as escolas, no entanto, optamos por realizar um experimento-piloto na Universidade de Brasília, intitulado Ateliê do Brincar. Este experimento teve lugar no Laboratório Imagens e $(\mathrm{m})$ Cena, e se constituiu em quatro encontros, ao longo do mês de novembro de 2017, com duração de um turno, que tiveram como temática central os elementos da natureza: terra, água, fogo e ar. O Ateliê foi aberto a crianças na faixa etária de 5 e 9 anos de idade, filhos e filhas de alunas, servidoras e professoras da UnB, além da comunidade em geral. No Ateliê atuaram diretamente os quatro estudantes de iniciação científica, a coordenadora do Projeto e a bolsista de Apoio Técnico.

A proposta de estimular o protagonismo das crianças através de jogos teatrais, brincadeiras tradicionais e brinquedos não-estruturados, a partir de temas específicos (no caso, os elementos da natureza), foi importante para a formação didática do grupo, já que todos participaram de todas as etapas, desde a organização dos planos de aula, compra e preparação dos materiais, realização das atividades e avaliação. Esta etapa foi fundamental para a compreensão, na prática, do que significa o protagonismo infantil: entendemos que para que esse se dê, espaços e tempos diferen-

${ }^{5}$ Contaram com bolsas de IC - UnB/CNPq - Ana Carolina de Sousa Castro, Dora Pinheiro Sales e Rodrigo Pereira Santiago dos Santos. Ingreth da Silva Adriano foi pesquisadora voluntária de IC e Luênia Guedes, atualmente mestranda em Artes Cênicas na UnB, atuou como bolsista de apoio técnico. 
ciados devem ser criados, a escuta deve ser ampliada e todos deveriam participar das atividades, sem distinção etária. Desta forma, brincadeiras, histórias, atividades artesanais, tudo foi compartilhado entre adultos e crianças. Entendemos, dessa forma, que o protagonismo não deve se restringir às crianças, mas a toda a rede de relações que envolve a comunidade escolar, e o/a educador/a tem um papel fundamental nesse processo. Como defende Helena Singer (2017, p 19): "para que o protagonismo do estudante se realize é preciso que seu educador também seja protagonista do próprio trabalho."

O terceiro momento foi a realização das práticas em escolas públicas do DF. Ana Carolina atuou na Escola Classe 405 Norte (Plano Piloto), Dora esteve no Centro de Ensino Fundamental CEF 04, localizado na Quadra 15 de Sobradinho e Rodrigo atuou no Centro de Educação Infantil da Ceilândia. Ingreth foi a única que não realizou a oficina em uma escola pública, mas no Centro Comunitário Social Tia Angelina, localizado no Varjão6. Estas práticas foram realizadas em uma relação de "coautoria" com as crianças, todas foram registrados através de diários de campo e, em alguns casos, audiovisual, e resultaram nos artigos de Iniciação Científica dos estudantes. Outro procedimento fundamental do processo foi a partilha das experiências entre os integrantes do projeto, nas reuniões quinzenais do Grupo de Pesquisa Imagens e(m) Cena. Não apenas o planejamento e a avaliação das aulas eram compartilhados, como também a prática em sala de aula, pois em muitos casos um colega mais experiente ou a professora acompanhava o/a jovem pesquisador/a na escola.

Além da prática nas escolas, no 1ํ. Semestre de 2018 realizamos nova etapa do Ateliê do Brincar, desta vez ligado aos Cursos Livres de Teatro da UnB. Durante as tardes de sábado realizamos atividades de sensibilização teatral com as crianças, baseadas nos Cinco Sentidos (olfato, audição, tato, paladar e visão) ${ }^{7}$. A metodologia utilizada, tanto nas escolas quanto no Ateliê do Brincar (com pequenas diferenças), envolvia a seguinte sequência: alongamento, contação de história, aquecimento com jogos tradicionais e inventados, atividades diversas com materiais não estruturados (de acordo com o tema do encontro), lanche, brincadeira do Limão e confecção do grande diário coletivo. É importante ressaltar que em todas as atividades procurávamos suscitar o protagonismo das crianças. No alongamento, por exemplo, pedíamos sugestões sobre formas de alongar o corpo; já nos jogos, propúnhamos adaptações inspiradas pela história que havia sido contada ou sugestões de jogos que as crianças desejassem naquele momento, e assim por diante. A "escuta" das crianças era nosso pressuposto fundamental.

Segue um exemplo de como a escuta e a observação atenta das crianças podem nos ensinar sobre o seu universo, contribuindo para o desenvolvimento de novas metodologias, mais adaptadas aos seus desejos e necessidades. Após uma aula que considerou "caótica", Dora, estudante de IC compartilhou com os/as colegas sua dificuldade em conseguir a atenção da turma de 3‥ Ano com a qual estava trabalhando. Uma colega então sugeriu que ela observasse o que as crianças mais gostavam de

\footnotetext{
6 Sobradinho, Ceilândia e Varjão são Regiões Administrativas do DF, coloquialmente conhecidas como "Cidades Satélite".

Grande parte das atividades foram registradas em fotografia, áudio e vídeo, com o devido consentimento dos pais e responsáveis.
} 
dizer e fazer em sala de aula. Ela então percebeu que a maioria dos meninos, que se recusava a participar das atividades propostas, adorava jogar "Bafo". Qual foi a solução que encontrou? Criou um jogo de cartas! ${ }^{8}$ Para trabalhar o tema da diversidade etária e física, ela desenhou cem cartinhas, com perguntas relacionadas ao universo dos idosos e dos deficientes. As cartas continham desafios físicos e perguntas que promovessem a afetividade, tais como: "Por que os velhinhos podem furar a fila?", "abra a porta com os cotovelos", "um surdo pode tocar um instrumento?", "passe uma rodada de olhos fechados", "diga uma qualidade de um colega da sala", entre outros. O jogo, assim, não apenas promoveu o encontro dos mundos por vezes tão afastados, de adultos e crianças, como também possibilitou um aprendizado corporificado e prazeroso e o surgimento de novas histórias: "Minha avó morava na roça e andava de pé no chão..." Essa aproximação com a "poética própria" das crianças permite vê-las, como propõe Marina Marcondes Machado, como performers de sua existência (Machado, 2010, p. 4).

Durante todos os encontros, como relatamos, havia um momento de contação de histórias e a partir dessas frequentemente surgiam debates sobre diversas questões. Destacaremos uma história que rendeu um belo debate. Em 2018, estávamos em clima de Copa do Mundo e um dos encontros com a turma de $2 \circ$. Ano da Escola Classe 405 Norte, de Brasília foi logo após o jogo do Brasil. Como todas as crianças estavam animadas com o evento, Ana Carolina, pesquisadora de IC, contou a história da Marta, jogadora da seleção Feminina de Futebol, que consta do livro "Histórias de Ninar para Garotas Rebeldes 2" (Favilli; Cavallo, 2018). A história foi contada sem mencionar o gênero da pessoa que virou uma grande jogadora de futebol. Quando a performance terminou, questionamos: vocês sabem quem é essa criança? E a maioria da turma respondeu: Neymar! Alguns ficaram incrédulos quando contamos que se tratava de Marta, uma mulher. E uma única criança, uma menina, exclamou: mas eu pensei que era uma mulher! Ninguém da turma nunca havia ouvido falar na jogadora e isso também rendeu um ótimo debate, no qual houve discordância entre os meninos: enquanto alguns achavam que não havia problema em mulheres jogarem futebol, outros já diziam que se uma menina quisesse entrar no seu time, não deixaria pela questão da velocidade. Exibimos também vídeos da jogadora e algumas crianças também questionaram a feminilidade da jogadora: "mas ela não parece mulher", "ela parece um homem" e o debate seguiu sobre o que definia feminilidade para as crianças...

Foi também no ano de 2018 que as atividades da pesquisa "Na Teia de Ananse"9 integraram o projeto "Crianças Protagonistas". Nessa pesquisa, realizada pela doutoranda Sonaly Torres Silva, buscamos investigar o ato de contar histórias em contextos educacionais no interior de Minas Gerais, tendo como ponto de partida performances de contação com temáticas afro-brasileiras. ${ }^{10}$ Consideramos que os contos africanos

\footnotetext{
8 O jogo funcionava da seguinte forma: seis crianças sentavam em roda e dividiam-se um número igual de cartas entre elas. Uma começava jogando uma carta no meio da roda e escolhia outra criança para "sofrer a consequência ou responder a pergunta". Depois era a vez da criança que estivesse à sua esquerda jogar uma carta, e assim sucessivamente. Quando uma criança jogasse a carta que tinha um desenho de uma velhinha, colocar a mão sobre a carta. Aúltima a colocar a mão levava todas as cartas. O objetivo, como no "bafo", era terminar sem nenhuma carta.

9 Pesquisa realizada com apoio da Coordenação de Aperfeiçoamento de Pessoal de Nível Superior - Brasil (CAPES) - Código de Financiamento 001.

10 Diferentes estudos e autores como Fernandes (2005), Silva (2011), Arena e Lopes (2013), Silva (2015 e 2016), Lima, Souza e Nascimento (2016), tem debatido e criticado a predominância da cultura de matriz europeia e a pequena presença dos personagens negros tanto em livros didáticos quanto em obras
} 
são fios potentes e relevantes na teia dessa pesquisa, pois podem contribuir para diálogos que valorizem a diversidade étnico-racial, especialmente consoante às crianças negras.

De acordo com o conto africano Ananse ${ }^{11}$, no início dos tempos não havia histórias na Terra. Todas pertenciam a Nyame, o Deus do Ceú. Ananse, o homem aranha, teceu um fio de prata do céu até a Terra e por ele subiu. Quando Ananse disse a Nyame que queria comprar as suas histórias, o Deus do céu colocou um preço muito alto, com grandes desafios que Ananse conseguiu vencer. Após entregar a Nyame o que lhe havia sido solicitado, o homem aranha desceu por sua teia de prata trazendo consigo o baú das histórias do céu para o povo de sua aldeia. Quando ele abriu o baú, as histórias se espalharam da África para os quatro cantos do mundo. Desde então as histórias fluem numa teia viva de infinitas conexões: emergem, se atravessam, se entrelaçam em diferentes experiências que compartilhamos, através de tatos, contatos, gestos, imagens, sensações, sons, palavras.

Assim, nossa pesquisa integra "Na Teia de Ananse" experiências de contação de histórias compartilhadas por atores/contadores de histórias, crianças e professoras em duas escolas públicas de Minas Gerais. Optamos pela pesquisa performativa (Haseman, 2015) pois esta permite que a criação e realização de performances com contos africanos, a escuta das histórias das crianças e os acontecimentos que podem emergir a partir destes encontros guiem tanto os processos quanto os produtos da pesquisa.

Priorizando uma perspectiva colaborativa, enfatizamos a participação de cada pessoa, a partir das suas práticas, de seus interesses e desejos (Desgagné, 2007). Nesse processo colaborativo cada instituição e cada sujeito participaram de forma singular, com diferentes níveis de envolvimento e intervenção nas atividades realizadas. Foram locus das ações as Escolas Municipais Joaquim de Ávila Neto, localizada em Coronel Fabriciano/MG, e a Hilda Morais, localizada em Belo Oriente/MG, ambas com Educação Infantil e Ensino Fundamental. Nessas escolas foram realizadas as seguintes práticas: criação e apresentação da performance de Contação de histórias - Na Teia de Ananse; Oficina de narrativas - No Baú de Ananse; Oficina de desenho e pintura - Histórias pintadas; Oficina de capacitação docente - Faz de Contos. Essas práticas estavam totalmente interligadas, se influenciavam mutuamente, como fios entrelaçados em uma teia com diversas ligações, cruzamentos, interferências. Todas as atividades realizadas nessa pesquisa envolvem um "engajamento do corpo" (Zumthor, 2002, p.18), uma atenção e escuta do corpo, seja através de uma atividade lúdica, um exercício de respiração, um movimento, uma ginga, o som de um instrumento, uma cantiga, um ritmo ou um instante de silêncio.

A criação e apresentação da Performance "Na teia de Ananse" foi realizada pela doutoranda e contadora de histórias Sonaly Torres Silva, juntamente com o ator-contador de histórias Roberto Yokel ${ }^{12}$. Essa atividade envolveu leituras dramáticas

\footnotetext{
literárias.

11 De acordo com Badoe e Diakite (2006), as histórias de Ananse integram a tradição do povo Axante, que habitava a região costeira da África Ocidental e se espalharam ocupando a região que hoje é conhecida como Gana. Esse conto africano disponível na íntegra em Rodrigues e Silva (2016, p. 18-24).

12 Roberto Yokel do Nascimento é professor de história, ator e contador de histórias. Atualmente é presidente da Associação Artística e Cultural de Coronel
} 
do conto Ananse; exercícios corporais e jogos teatrais; criação e ensaio da performance; criação de cenário e figurino. A apresentação dessa performance foi o elemento propulsor para tecer a teia com as demais atividades do projeto. Foi realizada junto a toda comunidade escolar (professoras, crianças, pais) que atuou como plateia-participante. A performance traz cantigas de capoeira e brincadeiras cantadas que se transformam conforme a participação da plateia. No decorrer do processo de apresentações houve, inclusive, a criação de novas brincadeiras cantadas, sugeridas pelas crianças, a inclusão de outros contos africanos, de histórias narradas pelas crianças e de um conto local apresentado pelas professoras. Ao todo aconteceram 11 apresentações da performance, em diferentes momentos da pesquisa, alcançando aproximadamente 660 crianças e 90 adultos.

As oficinas "No Baú de Ananse" foram realizadas com crianças, tendo como objetivo escutar suas histórias. Foram conduzidas pela doutoranda, em parceria com Roberto Yokel e com a artista plástica Ângela Ataíde. Contou também com a participação das professoras. As atividades da oficina integraram jogos corporais lúdicos; brincadeiras com ritmos, cantigas e movimentos de capoeira e cacuriá; desenhos livres; narração/escuta livre de histórias pelas crianças em pequenos grupos. Todo esse processo foi protagonizado pelas crianças: a escolha das atividades corporais e das brincadeiras cantadas era sempre realizada em conjunto com as crianças, no fluxo lúdico das atividades. A formação dos grupos para narrar/escutar as histórias foi realizada associando dois critérios, a similitude dos desenhos/temáticas das narrativas e a escolha das crianças. A forma de narrar e a ordem de apresentação de cada narrativa também foram definidos coletivamente pelas crianças, em cada grupo. Ao todo participaram dessa oficina 57 crianças, do $3^{\circ}$ ano e do $4^{\circ}$ ano do Ensino Fundamental. As narrativas foram gravadas e transcritas posteriormente pela pesquisadora. Após a transcrição houve a revisão dos textos junto às crianças. As histórias narradas foram publicadas em dois livros digitais: "No baú de Ananse: Contos Africanos e Narrativas de Crianças Brasileiras" e "Conta que eu Reconto - No baú de Ananse" (Silva, 2018a; 2018b).

O processo contou ainda com uma oficina de desenho e pintura - Histórias Pintadas - conduzida por Ângela Ataíde. Nesta oficina as crianças realizaram a criação e pintura de painéis coletivos a partir de seus desenhos livres individuais. Os painéis, que expressavam imageticamente os contos narrados pelas crianças, além de serem fotografados para ilustrar os livros digitais, também foram expostos para apreciação da comunidade escolar.

Considerando que o protagonismo infantil não ocorre de modo isolado, mas no âmbito da comunidade escolar e que será mais efetivo quando todos os membros da comunidade também assumam seu protagonismo, o projeto contemplou também uma oficina de capacitação docente - Faz de Contos. A oficina envolveu a apresentação da performance "Na teia de Ananse"; exercícios corporais lúdicos e jogos teatrais; desenho livre; escuta de histórias narradas pelos professores; diálogos e reflexões acerca da importância da contação de histórias africanas para crianças brasileiras, 
bem como da escuta das narrativas das crianças. Participaram dessa oficina 38 professores.

Dessa maneira, todas as atividades previam a partilha e a participação ativa de todos os membros da comunidade escolar. Mesmo sendo planejadas antecipadamente, no encontro com as crianças e professoras ganhavam novos contornos. As brincadeiras com cantigas provenientes da cultura afro-brasileira eram selecionadas em conjunto, seguindo o fluxo dos corpos, da alegria e do prazer, em escuta atenta à voz dos participantes, principalmente das crianças. Certo dia, por exemplo, ao iniciarmos a oficina de narrativas, perguntamos às crianças: como vamos começar hoje? Uma delas respondeu: - Com o Jabuti. Ela se referia a uma canção do Cacuriá13 que havíamos cantado na abertura da performance de contação de histórias no dia anterior:

\author{
Jabuti sabe ler, não sabe escrever. \\ Ele trepa no pau e não sabe descer \\ lê, lê, lê, lê, lê, lê. \\ Tô entrando... Tô saindo...
}

As demais crianças concordaram, então cantamos e incluímos a roda, a dança, a brincadeira corporal. Essa brincadeira levou Mariana, de 11 anos, a inventar uma nova versão para essa canção:

\author{
Era uma vez o Jabuti. \\ Ele não sabia escrever. \\ Ele subia na árvore e não sabia descer. \\ Aí, um dia, ele desceu e foi embora.
}

Percebemos, portanto, que a escuta das crianças, e a criação de tempos/espaços para a partilha concreta com elas, podem suscitar transformações nas dinâmicas escolares.

Aprendemos com Foucault (1987) que os contextos escolares se configuram de forma disciplinar, com técnicas que operam por meio da distribuição dos indivíduos no espaço, do controle do tempo e da ação, com estrutura e organização arquitetadas para a vigilância e o controle. A disciplina organiza um espaço analítico, composto de salas de aula organizadas com carteiras em fileiras, crianças hierarquizadas em turmas conforme idade, provas para progressão, que fazem com que a escola se constitua, ainda hoje, como uma máquina de vigiar, hierarquizar, recompensar, discriminar (Foucault, 1987). Nesse contexto, gestores educacionais (diretores, coordenadores pedagógicos) e professores também estão enredados dentro de enquadramentos disciplinares diversos. Entretanto, como defendia o autor, onde há poder, há escapadas, resistências.

Nesse sentido, observamos com Arroyo (2000) que professores e professoras, apesar de terem suas práticas enquadradas nesse contexto disciplinar, também vêm se construindo com gestos de autonomia, experiências criativas e inovadoras, pois a

\footnotetext{
13 O cacuriá é uma dança de roda do Maranhão, feita em pares, acompanhada por instrumentos de percussão. As canções integram versos improvisados respondidos por um coro de brincantes.
} 
escola é também um espaço de encontros entre diferentes gerações, sujeitos, culturas e subjetividades. Para o autor, por maiores que sejam os enquadramentos disciplinares a que são submetidos tanto os educadores quanto as crianças, em todas as escolas encontramos surpresas. Diante da normatização que busca coisificar, repetir, enquadrar conteúdos, educadores e educandos, as experiências de convívio e trocas humanas sempre instauram diferenças, produzem inovações. A inovação pedagógica emerge no encontro com as crianças concretas, que são singulares e não se repetem. Podem ser repetidas matérias, métodos, formas de organização das turmas, horários de aulas, o tempo curto do recreio, mas a vida que pulsa nas crianças é sempre diferente.

Temos consciência da assimetria de poder presente na relação adulto-criança, que coloca a infância numa posição subalterna face à geração adulta (Sarmento, 2005), principalmente em contextos escolares. Entretanto, sempre há escapadas, diferenças, sujeitos que não se sujeitam e não enquadram. Nessa perspectiva, uma criança que não obedece às regras, que inventa e realiza brincadeiras no tempo da aula, está criando rupturas, fendas pelas quais a diferença escapa, está produzindo resistência. Acreditamos que essa criança deveria ser escutada.

Dentre as formas de resistência possíveis no contexto escolar, podemos pensar que as experiências de partilha de histórias podem engendrar alternativas e contribuir para que as crianças sejam aceitas e respeitadas em sua singularidade.

A história "A Escola Nova", narrada por Ana Clara (9 anos), publicada no livro "No baú de Ananse: Contos Africanos e Narrativas de Crianças Brasileiras" (Silva, 2018a), nos oferece um exemplo desse olhar singular da criança sobre a escola:

\footnotetext{
A escola reformada já está pronta.

$\mathrm{Na}$ escola nova nós cantamos e fizemos atividades, brincadeiras, e mais...

Aí, nós andamos, andamos, andamos... E a gente brincou na pracinha.

E teve um lanche: pão com mussarela e presunto.

$\mathrm{E}$ a gente foi na biblioteca, pegou livros e foi na sorveteria. E ficamos felizes.
}

Essa história expressa um momento em que a escola que ela frequenta mudou para um prédio novo. Entretanto, ela nos apresenta uma escola nova não apenas em seu espaço físico, mas propõe a novidade em seu fazer pedagógico com a mistura de brincadeiras, lanche, livros, sorvetes e mais... Sua narrativa nos convida a olhar de forma diferente para a escola, a enxergar uma nova pedagogia, uma pedagogia performativa, que tenha mais sabores e movimento, que inclua o protagonismo das crianças cantantes, que andam e vão além das fronteiras físicas e disciplinares, além dos muros, das estruturas de salas de aulas e alcançam a "pracinha", local do brincar, imagem que tomamos como expressão de liberdade, campo de alegria.

Em sua narrativa, a pequena autora diz: "nós cantamos", "nós andamos"... Será que ao escutarmos esse "nós" na história, poderíamos imaginar professoras (adultas) e crianças, caminhando juntos nas experiências escolares, em uma relação menos hierarquizada, mais horizontal?

Essa possibilidade de quebra da estrutura hierárquica nos conduz a um conceito fundamental na obra de Victor Turner, um dos principais teóricos dos Estudos da Per- 
formance, a communitas. É pensando na operatividade desse conceito para debater nossas experiências performativo-pedagógicas que faremos o exercício que segue.

\section{Uma roda de histórias pode constituir uma communitas?}

Para refletir devidamente sobre essa questão, partiremos da descrição de uma experiência empírica: a performance do conto africano "A Lenda do tambor africano / O Macaquinho de Nariz Branco", apresentada junto a crianças de 6 a 10 anos em uma escola pública, na cidade de Antônio Dias/MG. Nessa performance, realizada por Roberto Yokel e Sonaly Torres Silva, os macaquinhos eram brincalhões, alegres e a contação integrava sons de tambores, cantigas de capoeira e brincadeiras tradicionais brasileiras. A certa altura da apresentação, Roberto, no fluxo do personagem macaquinho, impulsionado pelas gargalhadas das crianças, saiu do comportamento ensaiado e não parava de falar, de inventar, tornando impossível a continuidade da história. Sonaly então disse "estátua" e ele paralisou. Ela então pode continuar o conto... Quando o macaquinho estaria novamente em cena, ela disse: "des-estátua". E ele voltou a falar e a brincar como antes. Para avançar com a história, ela passou a dizer sempre "estátua!" Essa brincadeira não estava prevista na performance, mas as crianças entraram no fluxo e começaram a pronunciar as palavras estátua e des-estátua, modulando o ritmo de contação da história. A proposição de cada criança era aceita e respeitada pelos demais. Desta maneira, a performance não pertencia mais aos atores/contadores, estava sob o comando das crianças e fluía no acontecimento do encontro entre narrativa-contadores-crianças-brincadeiras-ritmos, era modulada coletivamente. Não apenas a performance ou a história se transformaram, mas também as pessoas que participavam, pois a divisão hierárquica entre contadores, professores, crianças, bem como os papeis definidos socialmente, se dissolveram. Naquela roda, todos brincavam prazerosamente, em um fluir coletivo que pode ser considerado similar a uma atmosfera de communitas.

O termo communitas é utilizado por Turner $(1974,2005,2015)$ em seus estudos sobre os processos rituais em sociedades tribais, para indicar um fenômeno emergente em situações liminares. Nestas, de acordo com Turner, as pessoas se encontram livres de suas posições, deveres e direitos instituídos cultural e socialmente, 0 que permite o surgimento de elementos subversivos e lúdicos. Assim, o límen suscita o pode ser, a hipótese, a fantasia, o desejo, agenciando cognição, afeto e vontade. Ele pode ser descrito como um caos frutífero, um campo de possibilidades, uma busca por novas formas e estruturas (Turner, 2005).

Segundo o autor, a palavra liminaridade, que inicialmente foi usada para denominar uma fase da estrutura de um rito de passagem, pode ser aplicada a outros aspectos da cultura, pois, "as pessoas brincam com os elementos familiares e os desfamiliarizam" em combinações inusitadas (Turner, 2015, p. 35). Richard Schechner (2011), grande parceiro de Turner no desenvolvimento teórico dos Estudos da Performance, aponta que a liminaridade em performance ocorre por meio de agenciamentos que conectam multiplicidades, envolvendo performers, espectadores, cenários, imagens, saberes, reunindo energias nas quais o ritmo e o tempo são coisas concretas, físicas, flexíveis, modulando fluxos, potencializando transformações. 
Considerando o que ocorreu durante a apresentação do conto "O Macaquinho de Nariz branco", acreditamos que performances de contação de histórias podem propiciar experiências de liminaridade. Na performance, a conexão narrativa-contadores-crianças-brincadeiras-ritmos possibilitou um momento liminar no qual emergiram contínuos processos de novas combinações, ou seja, cada conexão entre a apresentação dos contadores, o conto, a participação das crianças, os ritmos, as brincadeiras, os gestos, as palavras, produzia um novo arranjo. A brincadeira "Estátua" se transformou em outra coisa, as crianças assumiram o comando da experiência e passaram a modular o ritmo e as intensidades da contação, que foi integrando novas nuances e brincadeiras, suscitando novas significações, com uma atualização da história e uma subversão da própria performance.

De acordo com Turner (1974), no período liminar surge uma forma de relação social menos estruturada e relativamente indiferenciada, como uma comunidade, ou mesmo comunhão de indivíduos em situação de igualdade. Dessa maneira a communitas tem um caráter não estruturado e representa o instantâneo da inter-relação humana, que brota através dos interstícios da estrutura, em liminaridade. Quando a liminaridade é positiva, criativa, possibilita a emergência de uma modalidade de inter-relação humana na qual se pode brincar com os sistemas estruturais, de forma que haja uma subversão (ou mesmo aniquilação) de direitos e deveres, possibilitando uma atmosfera de communitas, na qual "todas as pessoas são percebidas como uma só, mesmo que apenas por um instante" (Turner, 2015, p. 64).

Vejamos como, na performance do conto "O Macaquinho de Nariz Branco", é possível observar a transformação dos sistemas estruturais da escola. O ambiente escolar constitui uma estrutura social em que as pessoas são segmentadas e hierarquizadas em seus papéis - as professoras e professores, as alunas e alunos e alunas, os/as profissionais do quadro técnico-administrativo, o/a diretor/a, os/as coordenadores/as pedagógicos/as - cada qual com seus direitos de deveres a serem cumpridos ordinariamente. A própria organização do espaço escolar demarca bem a estrutura desse sistema, conforme dissemos anteriormente, contudo, o momento da performance narrativa subverteu essa estrutura e abriu uma fissura liminar, engendrando uma pequena possibilidade de resistência.

A performance aconteceu no horário da "aula", ou seja, no tempo estruturalmente dedicado ao trabalho, entretanto, materializou a ludicidade através do conto vivo nos gestos, sons, movimentos, palavras, no encontro entre contadores e crianças-participantes, transformando o tempo de "trabalho" em tempo de brincadeira. A performance também rompeu os limites do espaço físico da sala de aula, pois foi realizada no pátio, um espaço aberto no qual não havia demarcação de lugares e todos (professoras, crianças, profissionais técnicos administrativos, diretora, coordenadoras pedagógicas) estavam sentados no chão, de forma circular, em um mesmo nível. Incialmente as docentes buscavam "manter a ordem", organizando as crianças conforme suas turmas de origem, porém, na medida em que a performance ia acontecendo, essas demarcações foram se alterando, as crianças trocavam de lugar, permanecendo apenas um limite tênue entre o espaço cênico dos performers e do público. Quanto mais entrávamos no fluxo da história, mais as estruturas iam se dissolvendo até que, no momento do jogo "Estátua", sob o protagonismo das crianças que comandavam os ritmos e tempos da performance, todos passamos a fazer parte de uma comunidade. Mais do que isso, de uma communitas. 
No final da performance, até o tênue limite do espaço cênico foi rompido e algumas crianças passaram a brincar com os instrumentos e elementos cênicos utilizados na contação. Percebemos que compartilhamos uma experiência de prazer, uma sensação de integração, de espontaneidade, o que nos aproxima da noção de communitas espontânea.

De acordo com Turner (2015), a communitas espontânea refere-se a um contato imediato, concreto, direto e total de seres humanos em uma interação pessoal. Ela tem algo de mágico, que nos leva a nos relacionarmos com os outros da maneira como se apresentam no aqui agora, livres dos papéis e obstáculos definidos socialmente, em estado de comunhão. Ao participar de situação de communitas espontânea seríamos "absorvidos em um evento singular, sincronizado e fluido" (Turner, 2015, p. 65).

Acreditamos que performances de contação de histórias, como as que temos procurado realizar em nossas pesquisas, propiciam a emergência de communitas espontâneas, nas quais a participação direta dos ouvintes é fundamental.

\section{É possível a emergência do protagonismo infantil em contextos de communitas?}

O ambiente escolar possui elementos que permitem caracterizá-lo como uma máquina disciplinar. Porém, como temos defendido desde o início deste texto, inspiradas por Foucault, onde há poder, há resistência. A escola é um espaço de educação. Maturana (1998) observa que mesmo sendo o educar um processo conservador, é nesse processo que a criança convive com o outro e, em convivência, se transforma. O autor aponta que "a criança vive o mundo em que se funda sua possibilidade de converter-se num ser capaz de aceitar e respeitar o outro a partir da aceitação e do respeito de si mesma" (idem, p.29). Então, é fundamental oportunizarmos experiências que impulsionem a emergência dessa aceitação e respeito. Consideramos que performances de contação de histórias em ambientes escolares, principalmente aquelas em as crianças assumem o protagonismo, criam e narram suas próprias histórias, podem oportunizar momentos de convivência nos quais as crianças podem se aceitar e aceitar os outros em suas diversidades. Por meio do relato dessas experiências observamos que pedagogias das artes cênicas que envolvam performances de contação de histórias podem engendrar communitas espontâneas. Nesse processo de deshierarquização das relações, as crianças conquistam tempos/espaços significativos no ambiente escolar, atuando como sujeitos ativos, narradores e protagonistas de ações e histórias. O protagonismo infantil, aqui, é pensado não como uma inversão das relações hierárquicas da escola, mas muito mais como uma possibilidade de equilíbrio destas. Os espaços e tempos de fala e de ação seriam, assim, melhor distribuídos, pois todos os atores sociais fazem parte da mesma comunidade. Ações protagônicas das crianças, promovidas no âmbito das pedagogias performativas, podem, portanto, representar estratégias de resistência ao poder tantas vezes opressor da "educação bancária", assim chamada pelo mestre Paulo Freire (2002) $)^{14}$.

\footnotetext{
14 Com essa expressão, Freire faz uma analogia (crítica) da educação com o sistema bancário, na qual os educandos seriam os depositários e o educador o depositante de saberes (Freire, 2002, p. 58).
} 
Não é possível avaliar o impacto das performances narrativas nos processos de subjetivação das crianças que as protagonizaram ou no cotidiano escolar como um todo. Entretanto, podemos questionar: diversas transformações, pequenas e momentâneas, podem produzir transformação nas estruturas socioculturais? Será que essas micro-transformações são capazes de produzir processos socioculturais que contribuam para construção de novas formas de ser e viver, que incluam a aceitação e o respeito a si e ao outro em sua diversidade? Acreditando em respostas positivas a essas questões, continuaremos agindo para viabilizar o que estamos chamando de "pequenas resistências", contando e ouvindo histórias COM as crianças.

\section{Referências}

ARENA, Dagoberto Buim; LOPES, Naiane Rufino. PNBE 2010: personagens negros como protagonistas. Educação e Realidade, Porto Alegre, v. 38, n. 4, 2013, p. 1147-1173.

ARROYO, Miguel G. Ofício de Mestre: imagens e auto-imagens. Petrópolis/RJ: Vozes, 2000.

BADOE, Adwoa e DIAKITE, Baba Wagué. Histórias de Ananse. São Paulo: Edições SM, 2006.

CRUVINEL, Tiago. Criança em cena: análise da atuação e de processos criativos com crianças-atores. Curitiba: Editora CRV, 2015.

DESGAGNÉ, Serge. O conceito de pesquisa colaborativa: a ideia de uma aproximação entre pesquisadores universitários e professores práticos. Revista Educação em Questão, Natal, v. 29, n. 15, 2007, p. 7-35.

FAVILLI, Elena; CAVALLO, Francesca. Histórias de Ninar para garotas rebeldes 2: 100 fábulas sobre mulheres extraordinárias. São Paulo: V \& R Editoras, 2018.

FERNANDES, José Ricardo Oriá. Ensino de História e diversidade cultural: desafios e possibilidades. Cadernos Cedes, v. 25, n. 67, 2005, p. 378-388.

FOUCAULT, Michel. Microfísica do poder. Rio de Janeiro: Graal, 1986.

FOUCAULT, Michel. Vigiar e punir: nascimento da prisão. Petrópolis/RJ: Vozes, 1987.

FREIRE, Paulo. Pedagogia do Oprimido. Rio de Janeiro: Paz e Terra, 2002.

GIRARDELLO, Gilka. Horizontes da autoria infantil: as narrativas das crianças na educação e na cultura. Boitatá - Revista do GT de Literatura Oral e Popular da ANPOLL. Londrina, n. 20, 2015, p. 14-27. 
HARTMANN, L. Pequenos narradores: experiências metodológicas com crianças contando histórias na sala de aula. In: Luciana Hartmann; Jorge das Graças Veloso. (Orgs.). O Teatro e suas Pedagogias: práticas e reflexões. 1ed.Brasília: Editora da UnB, 2016, v. 1, p. 259-280.

HARTMANN, L. Desafios da diversidade em sala de aula: um estudo sobre performances narrativas de crianças imigrantes. Cadernos CEDES, Campinas, v. 37, n. 101, 2017, p. $45-64$.

HARTMANN, L. Onça, veado, Maria: literatura infantil e performance em uma pesquisa sobre diversidade cultural em sala de aula. Educar em revista, Curitiba, v. 34, n. 67, 2018, p. 71-86.

HASEMAN, Brad. Manifesto pela Pesquisa Performativa. In: SILVA, Charles R.; FELIX, daina; et al (orgs). Resumos do 5 Seminário de Pesquisas em Andamento PPGAC/USP. São Paulo: PPGAC-ECA/USP, 2015, p. 41-53.

ICLE, Gilberto; BONATTO, Mônica T. Por uma Pedagogia Performativa: a escola como entrelugar para professores-performers e estudantes-performers. Cadernos CEDES, Campinas, v. 37, n. 101, 2017, p. 7-28.

LIMA, M. V. de; SOUZA, A. C. B. de; NASCIMENTO, C. G. do. Relações étnico-raciais: formação de professores e responsabilidade da universidade brasileira. In: SOUZA, A. C. B. de; OLIVEIRA, A. de S.; LIMA, M. V. de, (Orgs.). Educação para as relações étnico-raciais: identidades, etnicidades \& alteridades. Campina Grande-PB: Editora do CCTA, 2016.

MACHADO, Marina M. A criança é performer. Educação \& Realidade. Porto Alegre, v. 35, n. 2, 2010, p. 115-137.

MATURANA, Humberto R. Emoções e linguagem na educação e na política. Belo Horizonte, MG: UFMG, 1998.

PINEAU, Elyse Lamm. Nos cruzamentos entre a performance e a pedagogia: uma revisão prospectiva. Educação \& Realidade. Porto Alegre: n. 35, v. 2, 2010, p. 89-113.

RODRIGUES, Maria do Rosário de Fátima e SILVA, Sonaly Torres. Faz de contos: as crianças, os contos e o contar. Ipatinga: Edição das autoras, 2016.

SARMENTO, Manuel Jacinto. Gerações e alteridade: interrogações a partir da sociologia da infância. Educação e Sociedade, Campinas, v. 26, n. 91, 2005, p.361-378.

SCHECHNER, Richard. Performers e Espectadores - Transportados e transformados. Moringa. João Pessoa, v.2, 2011, p. 155-185. 
SILVA, Ana Célia da. A representação social do negro no livro didático: O que mudou? Por que mudou? Salvador: EDUFBA, 2011.

SILVA, da Eleonora Félix. Por uma educação para as relações étnico-raciais: entre desafios e possibilidades. In: OLIVEIRA, A.de S., SILVA da M. A. e AIRES, J. L. de Q. (Orgs.) Nas confluências do Axé: Refletindo os desafios e possibilidades de uma educação para as relações étnico-raciais. João Pessoa: Editora do CCTA, 2015.

SILVA, da Eleonora Félix. Possibilidades de abordagens sobre etnia no Ensino Fundamental. In: SOUZA, A. C. B. de; OLIVEIRA, A. de S.; LIMA, M. V. de, (Orgs.). Educação para as relações étnico-raciais: identidades, etnicidades \& alteridades. Campina Grande-PB: Editora do CCTA, 2016.

SILVA, Sonaly Torres (org.). No baú de Ananse: contos africanos e narrativas de crianças brasileiras. Belo Oriente/MG: FGPA, 2018a.

SILVA, Sonaly Torres (org.). No baú de Ananse: conta que eu Reconto. Coronel Fabriciano/MG: FGPA, 2018b.

SINGER, Helena. Pelo protagonismo de estudantes, educadores e escolas. In: LOVATO, A; YRULA, C. P.; FRANZIM, R. (orgs.). Protagonismo Infantil - a potência de ação da comunidade escolar. São Paulo: Ashoka/Alana, 2017, p. 14-21.

TURNER, V. W. O Processo Ritual: estrutura e antiestrutura. Petrópolis: Vozes, 1974.

TURNER, V. W. Dewey, Dilthey e Drama: um ensaio em Antropologia da experiência (primeira parte) de Victor Turner. Cadernos de Campo, n.13, 2005, p. 177-185.

TURNER, V. W. Do ritual ao teatro: a seriedade humana de brincar. Rio de Janeiro: Editora UFRJ, 2015.

ZUMTHOR, Paul. Performance, recepção, leitura. 2ed. São Paulo: Cosac Naify, 2002.

Recebido em: 15/11/2018

Aprovado em: 12/01/2019 